\title{
Prevalence of Glucose-6-Phosphate Dehydrogenase Deficiency in Neonates Hospitalized in Pasteur Hospital of Bam, Iran
}

\begin{abstract}
Mahtab Nejadaria (BSc)
Department of Laboratory Sciences, School of Medicine, Bam University of Medical Sciences, Bam, Iran, and Student Research Committee, Bam University of Medical Sciences, Bam, Iran

Seyed Mojtaba Mortazavi (MSc) Instructor of Bacteriology, School of Medicine, Bam University of Medical Sciences, Bam, Iran, and Student Research Committee, Bam University of Medical Sciences, Bam, Iran Mohammad Hasan Kohansal (PhD) Department of Medical Parasitology, School of Medicine, Bam University of Medical Sciences, Bam, Iran, and Student Research Committee, Bam University of Medical Sciences, Bam, Iran

Corresponding author: Mohammad Hasan Kohansal

Email: kohansalhasan@gmail.com

Tel: $\mathbf{+ 9 8 3 4 4 4 2 1 9 4 0 2}$

Address: School of Medicine, Bam University of Medical Sciences, Kerman, Iran
\end{abstract}

Received: 23 Apr 2019

Revised: 26 May 2019

Accepted: 26 May 2019

\section{(c) (i) (8)}

This work is licensed under a Creative Commons Attribution 4.0 License.

\begin{abstract}
Background and Objectives: The pentose phosphate pathway is of particular importance for energy supply in red blood cells. Glucose 6-phosphate dehydrogenase is the key enzyme involved in this pathway. The deficiency of this enzyme due to lack of nicotinamide adenine dinucleotide phosphate (NADPH) production in red blood cells leads to oxidation, hemoglobin deposition, red blood cell membrane changes and favism, which causes jaundice and hemolytic anemia in newborns. In this study, we evaluate the frequency of G6PID deficiency in newborns in a hospital in Bam, Iran.

Methods: In this descriptive-analytical cross-sectional study, blood samples were taken from 572 newborns hospitalized at Pasteur hospital of Bam (Iran) in the first half of 2018. Demographic data including gender and blood type were collected. The G6PD enzyme activity was evaluated using qualitative G6PI assay kit (Saba Teb, Iran). Data were analyzed using SPSS software.

Results: 0f the 572 cases examined, 52 (9.09\%) had 66PI deficiency. 0f the affected patients, $34(65.4 \%)$ were male and 18 (34.6\%) were female. In addition, the majority (47.7\%) of affected patients were with $0^{+}$blood group.

Conclusion: A relatively high frequency of G6PI deficient infants was reported in Bam. As expected, the prevalence of this disorder was higher in males than in females. Given the lost cost of screening, we suggest screening for G6PI enzyme activity in all newborns.

Keywords: Favism, Glucose 6-Phosphate Dehydrogenase, NADPH.
\end{abstract}

This paper should be cited as: Nejadaria M, Mortazavi SM, Kohansal MH [Prevalence of Glucose-6-Phosphate Dehydrogenase Deficiency in Neonates Hospitalized in Pasteur Hospital of Bam, Iran]. mljgoums. 2020; 14(2): $9-12$ 


\section{INTRODUCTION}

Red blood cells (RBCs) require various pathways in order to obtain necessary energy for circulating in blood vessels as well as for maintaining hemoglobin functions. Among these pathways, hexose monophosphate is an extremely pathway, which requires nicotinamide adenine dinucleotide phosphate (NADP) to reproduce reduced glutathione that protects erythrocytes from membrane and hemoglobin oxidation (1). Glucose 6phosphate dehydrogenase (G6PD) is a key enzyme involved in NADPH production. The deficiency of this enzyme leads to oxidation, hemoglobin deposition, red blood cell membrane changes and favism, which causes jaundice and hemolytic anemia in newborns (2). Glucose 6-phosphate dehydrogenase deficiency is an X-dependent hereditary disorder and mainly affects men (3). More than 40 million individuals suffer from G6PD deficiency worldwide (4). Lack of G6PD and various factors including infection, chemicals, some medications and fava bean can lead to acute hemolysis. The majority of patients with G6PD deficiency remain clinically asymptomatic in their lifetime. The risk of developing neonatal jaundice (NNJ) and acute hemolytic anemia following exposure to oxidative factors has increased. Glucose 6phosphate dehydrogenase-related NNJ rarely occurs at birth but is more common within the first three days after birth. Symptoms of hemolytic crisis often manifest with fatigue, asthenia, abdominal cramps and backache. Within the next hours and days, jaundice and dark colored urine may appear (4). In examination, the infant is pale, but in drastic cases, he/she may show symptoms of shock or rarely cardiac dysfunction (heart failure) (5). Considering the importance of jaundice and hyperbilirubinemia in infants and the lack of enough studies on prevalence of jaundice following G6PD deficiency, this study aimed to determine prevalence of G6PD deficiency in infants with NNJ in Pasteur hospital of Bam, Iran.

\section{MATERIAL AND METHODS}

This was a cross-sectional study performed on infants with hyperbilirubinemia who were hospitalized in Pasteur hospital (affiliated to the Bam University of Medical Sciences) of Bam during the first half of the year 2018. Demographic data including gender and blood type were recorded. Blood samples were collected in tubes containing EDTA under supervision of a pediatrician. The samples were immediately transferred to the laboratory. The G6PD enzyme activity was evaluated using qualitative G6PD assay kit (Saba Teb, Iran).First, blood samples were lyzed by distilled water, mixed with $0.2 \mathrm{ml}$ of tris buffer, and mixed thoroughly. Then, the mixture was left to dry until a dark blue color emerges at the bottom of the vial. Then, $5 \mathrm{ml}$ of hemolysis solution and one drop of determiner A were added to the vial. After amalgamating, some mineral oil was augmented. Next, the vial was placed in autoclave or water bath at $37{ }^{\circ} \mathrm{C}$ at dark according to the kit instruction. The vial was checked every 20 minutes for change in color. All data were collected and kept in a database. Informed consent was obtained from subjects' parents. Analysis of data was carried out in SPSS 18 and at significance level of 0.05 .

\section{RESULTS}

Of 572 newborns screened, $52(9.09 \%)$ had G6PD deficiency (Table 1).

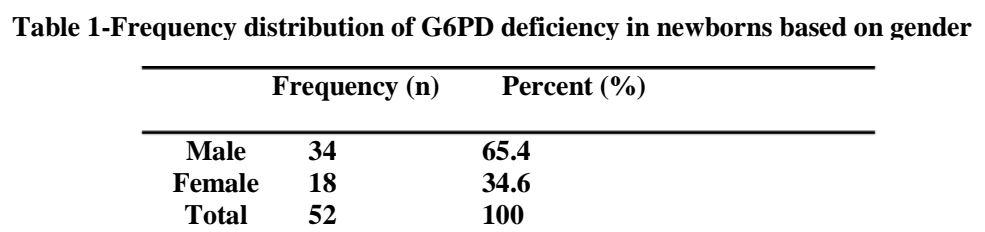

Table 2 shows the frequency distribution of newborns with G6PD deficiency based on blood type. The frequency of G6PD deficiency
Was highest among newborns who were $\mathrm{O}^{+}$ and lowest among those who were $\mathrm{B}^{+}$or $\mathrm{O}^{-}$

(Table 2.) 
Table 2- Frequency distribution of G6PD deficiency in newborns based on blood groups

\begin{tabular}{ccc}
\hline Blood groups & Frequency $(\mathbf{n})$ & Percent(\%) \\
\hline $\mathrm{A}^{+}$ & 9 & 20.5 \\
$\mathrm{~B}^{+}$ & 10 & 22.7 \\
$\mathrm{~B}^{-}$ & 2 & 4.5 \\
$\mathrm{O}^{+}$ & 21 & 47.7 \\
$\mathrm{O}^{-}$ & 2 & 4.5 \\
Total & 44 & 100 \\
\hline
\end{tabular}

\section{DISCUSSION}

The prevalence of G6PD deficiency differs based on geographical location. According to the World Health Organization, 2.9 to 7.5 percent of the human populations are affected with G6PD deficiency. Most affected cases (13 to 28 percent) live in Africa, and the prevalence of this disorder has been reported to be between 1 and 12 percent in USA and Europe (6). According to our results, the prevalence of G6PD deficiency was $9.09 \%$ among newborns at the Pasteur hospital of Bam, Iran. Of these patients, $65.4 \%$ were boy and $34.6 \%$ were girl. Numerous studies have been conducted to determine prevalence of G6PD deficiency in Iran. In a study by Firoozrai et al. in Tehran, the prevalence of this disorder was $16 \%$ among infants (1). Daliri et al. reported the prevalence of G6PD deficiency to be $15.58 \%$ among neonates living in malarious districts of Fars Province, Iran (7). In a study by Norbahksh et al. in Shahrekord, the rate of G6PD deficiency was $2.3 \%$. In this study, there was no correlation between incidence of neonatal G6PD deficiency and gender (5). Similar to our

\section{REFERECES}

1. Firoozrai M, Sedaghat kaboli Mr, Haghighi L. Determination Of Frequency Of Glucose-6-Phosphate Dehydrogenase (G6pd) Deficiency In Newborns With Hyperbillirubinemia. Razi Journal of Medical Sciences (Journal of Iran University of Medical Sciences). 1380; 8(23): 52-56.

2. Moray Rk, Bander D, Badem K, Kanli P, Radol V, Vil A. Harpers illustrated biochemistry. $1^{\text {st }}$ ed. Tehran. Ayyzh. 2012; 223-227.

3. Griggs Rc, Benjamin Ig, Fitz J.G, Wing Ej. Andreoli and Carpenter's Cecil essentials of medicine Ninth Edition Oncology and Hematology. $1^{\text {th }}$ ed. Tehran. Argmand book. 2016; 68-69.

4. Kasper D. Harrison's principles of internal medicine Hematologic Diseases. $1^{\text {st }}$ ed. Tehran. Teimorzadehpu Publishing House. 2015; 191-195.

5. Norbahksh Smk, Kasiri Ka, Jalil A, Hashem zade Chaleshteri M. Determining the frequency of glucose-6phosphate dehydrogenase deficiency in newborn infants in Shahrekord Journal of Shahrekord University of Medical Sciences 2013;15(5):30-37. study, a study in Qazvin reported the prevalence of G6PD to be 8.1 among neonates (8). In Nishapur, the prevalence of G6PD deficiency was $22.8 \%$ (9). In a study by Ghorashi et al., the prevalence of G6PD deficiency was $2.82 \%$ (10). In a study on two hospitals in Tehran, the prevalence of this disorder was $2.2 \%$ (11). In this study, $63 \%$ of infants with G6PD deficiency had type $\mathrm{A}^{+}$ blood group, while in our study, the frequency of G6PD deficiency was highest among newborns who were $\mathrm{O}^{+}$. In a study in Yazd, the frequency of G6PD deficiency in 105 infants with $\mathrm{NNj}$ was $18.1 \%$ (12).

\section{CONCLUSION}

Given the importance of early diagnosis for NNJ, the screening for G6PD enzyme activity in newborns seems essential.

\section{ACKNOWLEDGMENTS}

We would like to thank all those who cooperated with us in this research.

\section{CONFLICT OF INTEREST}

There is no conflict of interest to declare.

6. Nazari, H, Habibeh Najar, H, Emadi, A, Abasi, Y, Salehiyan, A, Monem, M, et al. Prevalence of G6PD deficiency in neonates referred to Semnan University of Medical Science's screening Lab. mljgoums. 2011; 5(2): 66-70. [Persian]

7. Daliri S, Asadollahi K, Rahimi N, Sayehmiri K. Incidence of glucose-6-phosphate dehydrogenase deficiency in malaria-prone regions of Fars province. Tehran Univ Med J. 2017; 75 (9) :669-674.

8. Sarrashtehdari M, Doulatshahi L. Determination of G6PD deficiency in icteric neonates. J Qazvin Univ Med Sci. 2003; 7 (1): 38-41.

9. Mehrzad J, Motavallizadeh Kakhaki A. Determination of the Prevalence Rate of Glucose-6-Phosphate Dehydrogenase Deficiency in Neyshaboor . RJMS. 2005; 12 (45) : 155-162.

10. Ghorashi Z, Soltani H, Ghorashi S. Glucose-6Phosphate Dehydrogenase Deficiency in Icteric Neonates Admitted in Tabriz Pediatric Medical Center. Medical journal of tabriz university of medical sciences. 2007; 29(3): 89-93.[Persian] 
11. Kazemi A, Nowrozi H, Tohidi Moghaddam M, Naderloo Ar. Prevalence of Glucose-6-phosphate dehydrogenase (G6PD) deficiency of newborns in Rasol Akram and Ali Asghar hospitals of Tehran. Bushehr University of Medical Sciences and Health Services. 2013; 16(1): 61-68.
12. Pahlavanzadeh M, Hekmatimoghaddam S, Ardestani MT, Ghafoorzadeh M, Aminorraaya MM. G6PD enzyme deficiency in neonatal pathologic hyperbilirubinemia in Yazd. Iranian journal of pediatric hematology and oncology. 2013; 3(2): 69. 